\title{
Study by Absorption and Emission \\ Spectrophotometry of the Efficiency of the Binary \\ Mixture (Ethanol-Water) on the Extraction of Betanin from Red Beetroot
}

Mohammed El-Amine NOUAIRI ( $\nabla$ nouairi.medamine@univ-mascara.dz )

Mustapha Stambouli University of Mascara https://orcid.org/0000-0003-1931-271X

Mohammed FREHA

Mustapha Stambouli University of Mascara

Ali BELLIL

Mustapha Stambouli University of Mascara

\section{Research Article}

Keywords: Extraction analysis, Betanin, Red beetroot, Absorption and Emission Spectrophotometry.

Posted Date: February 25th, 2021

DOl: https://doi.org/10.21203/rs.3.rs-255890/v1

License: (1) (i) This work is licensed under a Creative Commons Attribution 4.0 International License.

Read Full License 


\section{Abstract}

In this paper, we intend to present a method of extraction and analysis of betanin from Algerian red beetroot, and to know the efficiency of the binary mixture (Ethanol-Water) on the extraction. This dye is a natural pigment with high antioxidant power and widely used as a natural dye. In addition, the high bioavailability of this pigment reinforces its potential for future therapeutic applications. However, the betanin content of commercially available beet extracts never exceeds $1.2 \%$ and this molecule does not exist marketed in a more purified form, it is therefore necessary to have efficient tools for the enrichment of betanin extracts. The experimental results made in our laboratory, confirm the effectiveness of the binary mixture (Ethanol-Water) on the extraction of betanin from Algerian beetroot.

\section{Introduction}

Vegetable beet (Beta vulgaris L.) has the notable scientific interest, because it is a rich source of nitrate $\left(\mathrm{NO}_{3}\right)$, a compound with advantageous cardiovascular health effects through the endogen production of nitric oxide $(\mathrm{NO})^{1,2}$.

Beetroot is the chief source of betalains ${ }^{4-12}$ which is a water-soluble nitrogen pigment with heterocyclic ring, which can be further subdivided into two classes depending on chemical structure: betaxanthins comprising indicaxanthin; vulgaxanthin I and II, accountable for orange-yellow coloring; and betacyanins, such as betanin whish is a glucose heteroside (betanidine 5-0-glucose), and its aglycone is betanidine (Figure 1, 2), isobetanin, neobetanin, and prebetanin, accountable for red-violet coloring ${ }^{4,5}$. It is the best source for extracting the red color. Mainly using beetroot has several characteristics, including, for example the solubility in water, the stability over a $\mathrm{pH}$ range of $3-7$, and it often used to color low-acid foods, and exist primarily in fruits and flowers, including a variety of fluorescents ${ }^{6-20}$.

However, Betanin is the main component of the red dye extracted from beets which accounts for approximately $75-95 \%$ of all coloring matter found in beets ${ }^{4-10}$. It is available in the root beetroot, which is used as a coloring additive in foods ${ }^{20-27}$. It gives foods a desirable red color and has multiple uses in foods. In addition, betanin exists as an internal salt as a zwitterion in beet vacuoles. It is an anthocyanin which is a water soluble dye and gives colors ranging from purple and blue, to most shades of red. The

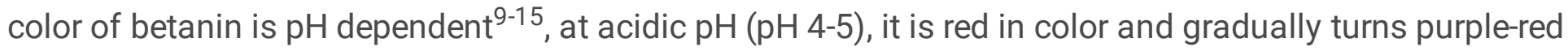
as the $\mathrm{pH}$ decreases (Figure 3). At alkaline $\mathrm{pH}(\mathrm{pH}$ 11-12) betanin hydrolyzes and becomes yellow-brown in color (Figure 4). It is poorly soluble in oil (lipophilic) ${ }^{5-14}$ and is soluble in water and ethanol (hydrophilic) $)^{5-14}$. Recently, medical researchers have discovered that betanin has bioactive properties such as an antioxidant, antimicrobial and anticancer ${ }^{4,28,29}$.

Generally, the principal method used to isolate red food coloring is solid-liquid extraction, a process commonly used in the food industry. Being a water soluble pigment, betanin can be extracted from red 
beets using any of the following solvents: acidified water, water-alcohol mixture or acidified alcoholic solution ${ }^{16}$. For example, Neagu and Barbu ${ }^{17}$ studied the betanin extraction from beetroot using different solvent systems by solid-liquid extraction technique. These results revealed that the highest betanin content of around $20 \mathrm{mg} / \mathrm{g}$ of beet was obtained with the use of a weak acid solution (using $0,5 \%$ citric acid $+0,1 \%$ ascorbic acid). In addition, they extracted the considerable amount of betanins using added solutions of ascorbic acid.

\section{Analytical Extraction And Characterization}

The separation method is physical, where ethanol and water were used as extraction solvents at different percentages in order to have a very good extraction yield and to observe the degree of selectivity of these solvents with respect to others previously used ${ }^{27}$. Commercially available Algerian beet has been used as extraction material. This plant material was raped and then filtered to obtain a juice from the beetroot. The extraction was carried out at $25^{\circ} \mathrm{C}$ with a time of 3 minutes. Before performing the spectrophotometric analyzes, several dilutions were prepared to obtain high resolution spectra. The dilution factor is around $1 / 4$.

The following solvents were used in the first series of experiments:

- Solution (20\% Distilled water - $80 \%$ Ethanol)

- Solution (20\% Ethanol - $80 \%$ Distilled water)

- Solution (40\% Distilled water - 60\% Ethanol)

- Solution (40\% Ethanol - 60\% Distilled water)

The used analysis methods are UV-Vis absorption spectrophotometry and emission spectrophotometry, the aim of which is to know the maximum wavelength absorbed or emitted by betanin extracted from beetroot. In addition, the amount of betanin extracted from $40 \mathrm{~g}$ of beet is calculated using the equation below (Eq.1).

$$
\mathrm{m}_{\mathrm{i}}=\frac{\mathrm{A}_{\mathrm{i}} \mathrm{F}_{\mathrm{d}} \cdot \mathrm{M}}{\varepsilon \cdot 1} \cdot \frac{\mathrm{V}_{\mathrm{e}}}{1000 \cdot \mathrm{m}_{\mathrm{s}}}
$$

Where:

$\mathrm{m}_{\mathrm{i}}$ : quantity of betanin extracted per $40 \mathrm{~g}$ of red beet used,

Ai: Sample absorption,

M: average molecular mass (550 g.mol ${ }^{-1}$ for betanin),

$\varepsilon$ : molar extinction coefficient (1120 L.cm ${ }^{-1}$. mole ${ }^{-1}$ for betanin $)^{21}$, 
$\mathrm{V}_{\mathrm{e}}$ : Volume of extract in $\mathrm{ml}$ (after extraction),

$\mathrm{m}_{\mathrm{s}}$ : mass of red beet used for extraction,

$F_{d}$ : Dilution factor (1/4).

\section{Experimental Results And Discussion}

The experimental results are expecting for the efficient extraction of betanin from beets. The UV-Vis absorption spectra of red beet extracts at different percentages of the solvents used are visible in the figure below (Figure 5). The shapes of the spectra show two peak centers (shoulder) at the wavelengths shown in the table below (Table 1).

From the results that we found (Table 1), we notice that betanin has an absorption maximum varying from $480 \mathrm{~nm}$ to $540 \mathrm{~nm}$ (Figure 5) and indeed our found values confirm the data of the literature ${ }^{16,17}$. As a result, when the binary mixture (Ethanol-Water) is used to extract betnin from red beet with a high percentage of water (80\%), we've found an absorption band at $535 \mathrm{~nm}$ and that it is the same value found when using a mixture (Ethanol-Water) with a low percentage of water $(20 \%)$. For the mixture (EthanolWater) content $40 \%$ of water and $60 \%$ of ethanol, the maximum absorption wavelength appears at $539 \mathrm{~nm}$, however, for $60 \%$ water and $40 \%$ ethanol, the maximum absorption wavelength appears at $537 \mathrm{~nm}$. According to researches results ${ }^{16,17}$, they showed that the maximum absorption limit of betanin occurs at a wavelength of $538 \mathrm{~nm}$ at $\mathrm{pH} 5$. In addition, they concluded that the aqueous extracts mainly contain betanidine and that the ethanolic extract mainly contains betanin, where a strong absorption band is observed at about $530 \mathrm{~nm}$ in the visible range for beetroot juice which has been attributed to the betanin pigment.

In addition, an absorption band is observed at $532 \mathrm{~nm}$ in the visible region using ethanol as a solvent. In addition, an absorption band at approximately $542 \mathrm{~nm}$ with the intensity of absorption maxima for aqueous extracts is approximately equal, greater than the ethanolic extract. Thus, the researchers concluded that for the aqueous extract the second band had an absorption maximum at $515 \mathrm{~nm}$ and for the aqueous extract at $509 \mathrm{~nm}$. These bands are only seen in the highly concentrated extract, and it disappears when the solution is diluted. Indeed, our analysis results by UV-Visible absorption spectrophotometry confirm their results.

For the absorbance given in Table 1, when using a mixture (Ethanol-Water) with a high percentage of water, the absorbance value exceeds 2 moles $^{-1} \cdot \mathrm{cm}^{-1}$; this explains why betanin is soluble in a mixture (ethanol-water) with a high percentage of water ( $80 \%$ water- $20 \%$ ethanol). It is also noted that the quantities extracted from beet betanin are variable depending on the percentages of solvents used. The solvents (Ethanol-Water) used with a high percentage of water can extract a large amount of betanin from beetroot, i.e. approximately $3.42 .10^{-4} \mathrm{~g} / \mathrm{ml}$. 
On the other hand, the UV-Vis emission spectra of beet extracts with the same percentages of solvents used are visible in Figure 6. It is known that betanin absorbs at $537 \mathrm{~nm}$ and emits at a wavelength longer than that absorbed. In order to know the value of the wavelength in which it will be emitted, we have chosen an emission range varying from $480 \mathrm{~nm}$ to $900 \mathrm{~nm}$, so that the value of the wavelength necessary to make this molecule excited must be less than $537 \mathrm{~nm}$. From the emission spectra obtained, it is observed that when a mixture (Ethanol-Water) with a small percentage of ethanol is used, the emission peak of this molecule appears at $537 \mathrm{~nm}$ which is the same absorbed value. Also, when using a mixture (Ethanol-Water) with a high percentage of ethanol, this peak disappears, where it appears at $800 \mathrm{~nm}$. Therefore, we can say that the maximum betanin emission limit occurs at a wavelength of $800 \mathrm{~nm}$ when using a mixture (Ethanol-Water) with high percentages of ethanol and low in water.

TABLE 1 Values of \% in Ethanol /\% in water $\left(\mathrm{X}_{\mathrm{Ethanol}}, \mathrm{X}_{\mathrm{water}}\right)$, volume of the extract in betanin (Ve), mass of solid beetroot

$\left(\mathrm{M}_{\text {Beetroot }}\right)$, calculated mass of betanin $\left(\mathrm{M}_{\text {Betanin }}\right)$, wavelengths maximum absorbed $\left(\lambda_{\max 1,2}\right)$ and maximum absorbances $\left(\mathrm{A}_{\text {max } 1,2}\right)$

\begin{tabular}{lllll}
\hline $\mathrm{X}_{\text {Ethanol }}$ & $80 \%$ & $60 \%$ & $40 \%$ & $20 \%$ \\
$\mathrm{X}_{\text {water }}$ & $20 \%$ & $40 \%$ & $60 \%$ & $80 \%$ \\
$\mathrm{~V}_{\mathrm{e}}(\mathrm{ml})$ & 40,8 & 31,2 & 31,2 & 40,8 \\
$\mathrm{M}_{\text {Beetroot }}(\mathrm{g})$ & 40 & 40 & 40 & 40 \\
$\mathrm{\lambda}_{\text {max1Absobed }}(\mathrm{nm})$ & 478,5 & 481,5 & 480,5 & 480,5 \\
$\mathrm{~A}_{\max 1}$ & 1,502 & 1,070 & 2,787 & 2,734 \\
$\lambda_{\max 2 A b s o r b e d}(\mathrm{~nm})$ & 535 & 539 & 537 & 535 \\
$\mathrm{~A}_{\max 2}$ & 1,395 & 1,279 & 2,872 & 2,548 \\
$\mathrm{M}_{\text {Betanin }}(\mathrm{g} / \mathrm{ml})$ & $1,88.10^{-4}$ & $1,2.10^{-4}$ & $2,75.10^{-4}$ & $3,42.10^{-4}$ \\
\hline
\end{tabular}

\section{Conclusion}

The method of extracting betanin from Algerian beetroot, where ethanol and water are used as high water percentage extraction solvents, gives a good extraction yield. UV-Visible absorption spectrophotometry of the beet extract confirmed that betanin has an absorption maximum varying from $480 \mathrm{~nm}$ to $540 \mathrm{~nm}$. The analyses by UV-Visible emission spectrophotometry of the beet extract are showed that the maximum betanin emission limit occurs at a wavelength of $800 \mathrm{~nm}$ where ethanol and water are used as extraction solvents at high percentages of ethanol and low in water.

\section{Declarations}

\section{Competing interests:}

The authors declare no competing interests. 
Author's name and Affiliation:

M. NOUAIRI

Process Engineering and Solution Chemistry Laboratory (LGPS), Faculty of Sciences and Technology, University Mustapha Stambouli of Mascara, Mascara - Algeria.

MM. FREHA

Process Engineering and Solution Chemistry Laboratory (LGPS), Faculty of Sciences and Technology, University Mustapha Stambouli of Mascara, Mascara - Algeria.

\section{A. BELLIL}

Process Engineering and Solution Chemistry Laboratory (LGPS), Faculty of Sciences and Technology, University Mustapha Stambouli of Mascara, Mascara - Algeria.

\section{References}

1. Baião DDS, Silva DVTD, Aguila EMD, Paschoalin VMF. Nutritional, bioactive and physicochemical characteristics of different beetroot formulations. In: Food Additives. InTech;. pp. 1-24 (2017).

2. da Silva DVT, dos Santos Baião D, de Oliveira Silva F, Alves G, Perrone D, Del Aguila EM, et al. Betanin, a natural food additive: Stability, bioavailability, antioxidant and preservative ability assessments. Molecules.; 24(3):458 (2019).

3. Hanssen Maurice. ; E comme Additif, produits chimiques au menu. ; Edition Flammarion, pp.156 (1988).

4. Azeredo HMC. Betalains: Properties, sources, applications, and stability-A review. International Journal of Food Science and Technology; 44(12): 2365-2376 (2009).

5. Tumbas Šaponjac V, Čanadanović- Brunet J, Ćetković G, Jakišić M, Djilas S, Vulić J, et al. Encapsulation of beetroot pomace extract: RSM optimization, storage and gastrointestinal stability. Molecules.;21(5):584 (2016).

6. F. Gandía-Herrero, J. Escribano, F. García-Carmona, Planta, 222, 307 (2005).

7. M. C. Madhusudhan, K. S. M. S. Raghavarao, Aqueous Two-Phase Extraction for the Recovery of Beet Pigments and Enzymes, in Red Beet Biotechnology: Food and Pharmaceutical Applications, Springer, pp. 393408 (2012).

8. Strack D., Vogt T., Schliemann W.; Recent advances in betalain research, Phytochemistry, 62, pp. 247269 (2003).

9. Nowacki $L$ et al.; Betanin-enriched red beetroot (Betavulgaris L.) extract induces apoptosis and autophagic cell death in MCF-7 cells; Phytother; 29, 1964-73 (2015).

10. F. Delgado-Vargas, A. R. Jiménez, O. P. López, Crit. Rev. Food Sci. Nutr., 40, 173 (2000). 
11. Y. Cai, M. Sun, H. Corke, J. Agric. Food Chem., 51, 2288 (2003).

12. 1 Schwartz S.J., Von Elbe J.H., J. Agric. Food Chem., 23, pp.540 (1980).

13. O. Kanner, S. Harel, R. Granit, J. Agric. Food Chem., 49, 5178 (2001).

14. Butera D., Tesoriere L., Gaudio F. Di., Bongiorno A., Allegra M., Pintaudi A.M., Kohen R., Livrea M.A. ; J. Agric. Food Chem., 50, pp. 6895 (2002).

15. Pedreno M.A., Escribano J. ; Correlation between antiradical activity and stability of betanin from Beta vulgaris $L$ roots under different temperature, $\mathrm{pH}$ and light conditions, Journal of the Science of Food and Agriculture, 81, pp. 627-631 (2001).

16. Adina Popa, Bianca Moldovan, Luminita David, “Betanin from Red Beet (Beta vulgaris L.), Extraction conditions and evaluation of the thermal stability, Babe-Bolyai" University, Faculty of Chemistry and Chemical Engineering, 11 Arany Janos Str., 400028, Cluj-Napoca, Romania.

17. Neagu C, Barbu V. Principal component analysis of the factors involved in the extraction of beetroot betalains. Journal of Agroalimentary Processes and Technologies.; 20(4):311-318 (2014).

18. Multon J-L. ; Additifs et auxiliaires de fabrication dans les industries agroalimentaire. ; Collection Sciences et Techniques Agroalimentaires. ; Edition TEC\&DOC, pp.746 (1998).

19. Yi-Zhong Cai, Mei Sun, Harold Corke. ; Characterization and application of betalain pigments from plants of Amaranthaceae; Trends in Food science \& Technology, 16, pp.370-376 (2005).

20. Tiwari, B. K.; Cullen, P. J. Extraction of Red Beet Pigments. In: Red Beet Biotechnology, B. Neelwarne (Ed.) Springer, Boston: pp. 373-391 (2013).

21. Socaciu C.; Food colorants. Propriétés chimiques et fonctionnelles, CRC Press, New York (2008).

22. Stintzing F.C., Schieber A., Carle R. ; Betacyanins in fruits of red-purple pitaya, Hylocereus polyrizus (Weber) Britton \& Rose, Food Chemistry, 77, pp. 101-106 (2002).

23. Stintzing, F. C.; Carle, R. Betalains in food: Occurrence, stability, and postharvest modifications, Socaciu, C. (Ed.), Food Colorants: Chemical and Functional Properties, CRC Press, Boca Raton: pp. 227-299 (2008).

24. Betanin:A Red-Violet Pigment-Chemistry and Applications DOI:http://dx.doi.org/10.5772/intechopen.88939.

25. Frederick J. Francis; Encyclopedia of Food Science and Technology; Second Edition, 1, John Willey \& Sons, Inc. (2000).

26. Dobre T., Floarea O.; Separarea compuşilor chmici din produse natural; (Separation of chemical compounds from natural products); Edit. Matrix ROM, Bucuresti (1997).

27. Dumbrava A, Enache I, Oprea Cl, Georgescu A, Girtu MA. Toward a more efficient utilisation of betalains as pigments for dye-sensitized solar cells. Digest Journal of Nanomaterials and Biostructures.;7(1):339-351 (2012).

28. Castellar R., Obón JM., Alacid M., Fernández-López JA ; Color properties and stability of betacyanins from Opuntia fruits. J. Agric. Food Chem.; 51, pp.2772-2776 (2003). 
29. Stintzing FC., Herbach KM., Mosshammer MR., Carle R., Yi W., Sellappan S., Akoh CC., Bunch R., Felker $\mathrm{P}$; Color, betalain pattern, and antioxidant properties of cactus pear (Opuntia spp.) clones ; J. Agric. Food Chem.; 53 pp.442-451 (2005).

30. Delgado-Vargas F., Jiménez A. R., Paredes-López O., "Natural pigments: carotenoids, anthocyanins, and betalains characteristics, biosynthesis, processing, and stability", Crit.Rev. Food Sci. Nutr., 40(3), 173-289 (2000).

31. Gon.alves, L. C. P.; de Souza Trassi, M. A.; Lopes, N. B.; Dorr, F. A.; dos Santos, M.T.; Baader, J. W.; Oliveira Jr., V. X.; Bastos, E. L. A comparative study of the purification of betanin, Food Chem., 131 231-238 (2012).

32. Nemzer, B.; Pietrzkowski, Z.; Spórna, A.; Stalica, P. W.; Thresher, W.; Micha.owski,T.; Wybraniec, S. Betalainic and nutritional profiles of pigment-enriched red beet root (Beta vulgaris L.) dried extracts, Food Chem. 127, 42-53 (2011).

33. Manchali, S.; Murthy, K. N. C.; Nagaraju, S.; Neelwarne, B. Stability of Betalain Pigments of Red Beet. In: Red Beet Biotechnology, B. Neelwarne (Ed.) Springer, Boston: pp.55-74, (2013).

34. Chandran, J.; Nisha, P.; Singhal, R. S.; Pandit, A. B. Degradation of colour in beetroot (Beta vulgaris L.): a kinetics study, J. Food Sci. Technol. 51, 2678-2684 (2014).

35. Esatbeyoglu, T.; Wagner, A. E.; Schini-Kerth, V. B.; Rimbach, G. Betanin-A food colorant with biological activity, Mol. Nutr. Food Res. 59, 36-47 (2015).

36. Khan, M. I. Stabilization of betalains: A review, Food Chem. 197 1280-1285 (2016).

37. Cortez, R.; Luna-Vital, D. A.; Margulis, D.; Gonzalez de Mejia, E. Natural Pigments: Stabilization Methods of Anthocyanins for Food Applications, Compr. Rev. Food Sci.Food Saf. 16, 180-198 (2017).

\section{Figures}




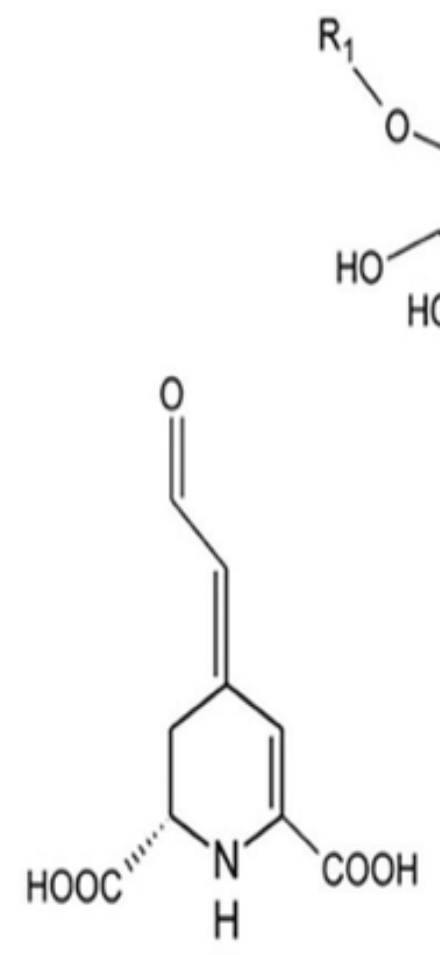

(a)

(b)

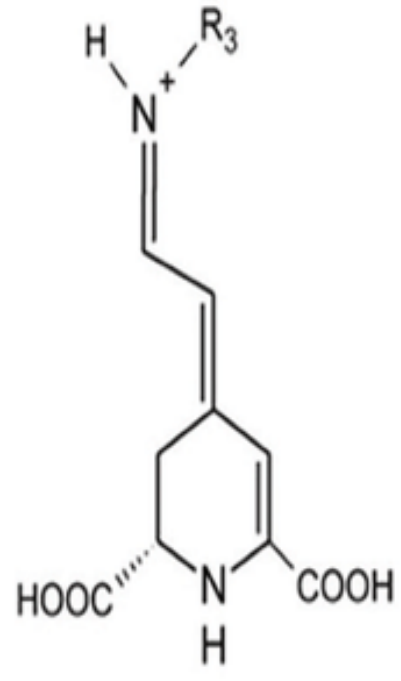

(c)

Figure 1

Betalamic acid (a), betacyanins (b) and betaxanthins (c) 


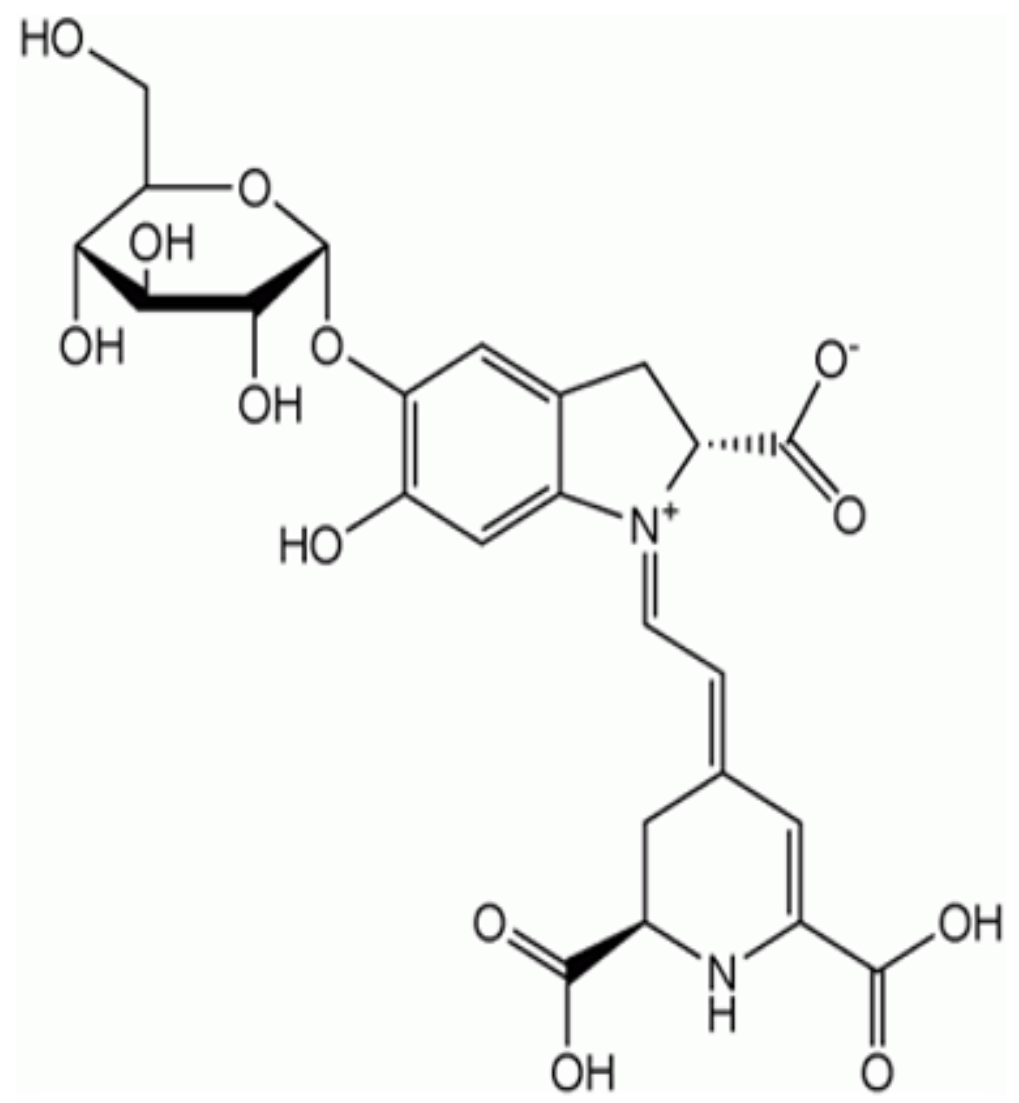

Figure 2

Structure of Betanin 


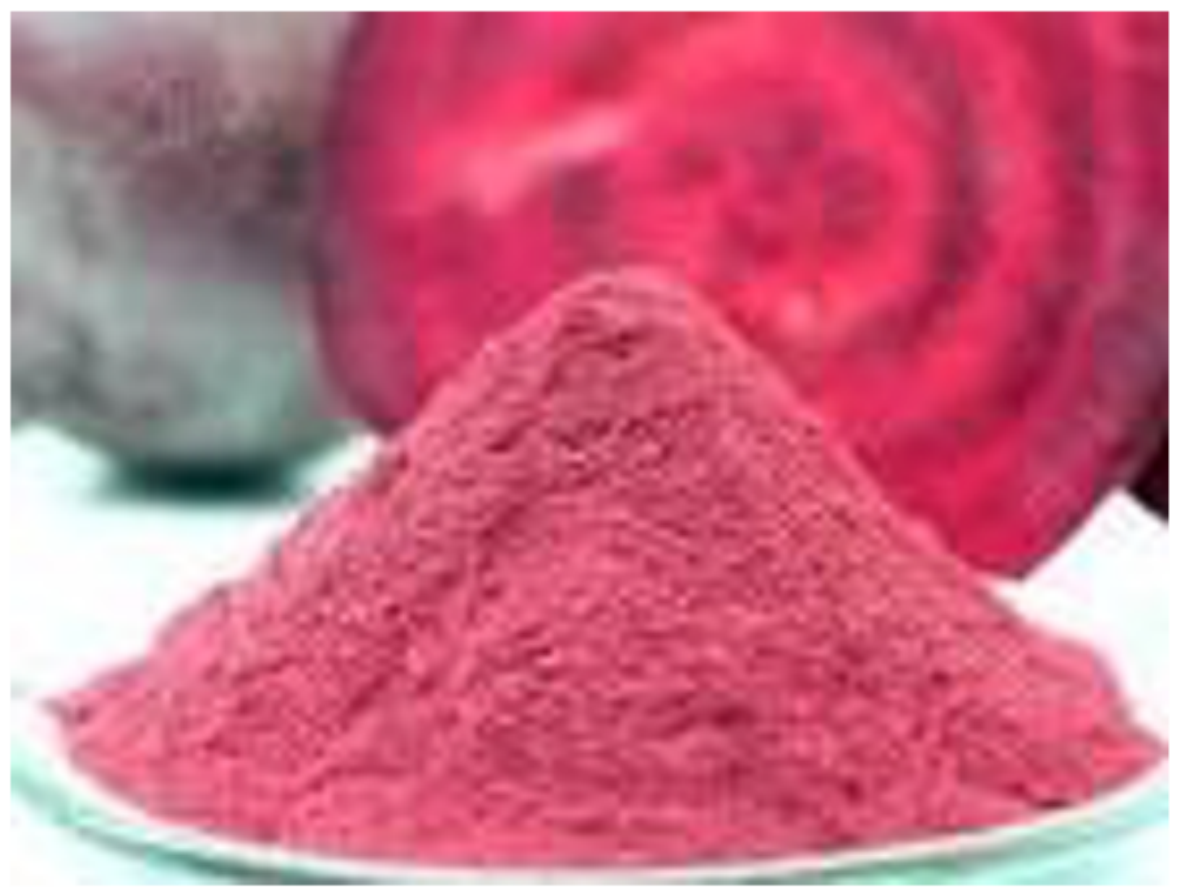

Figure 3

Betanin powder of purple-red color

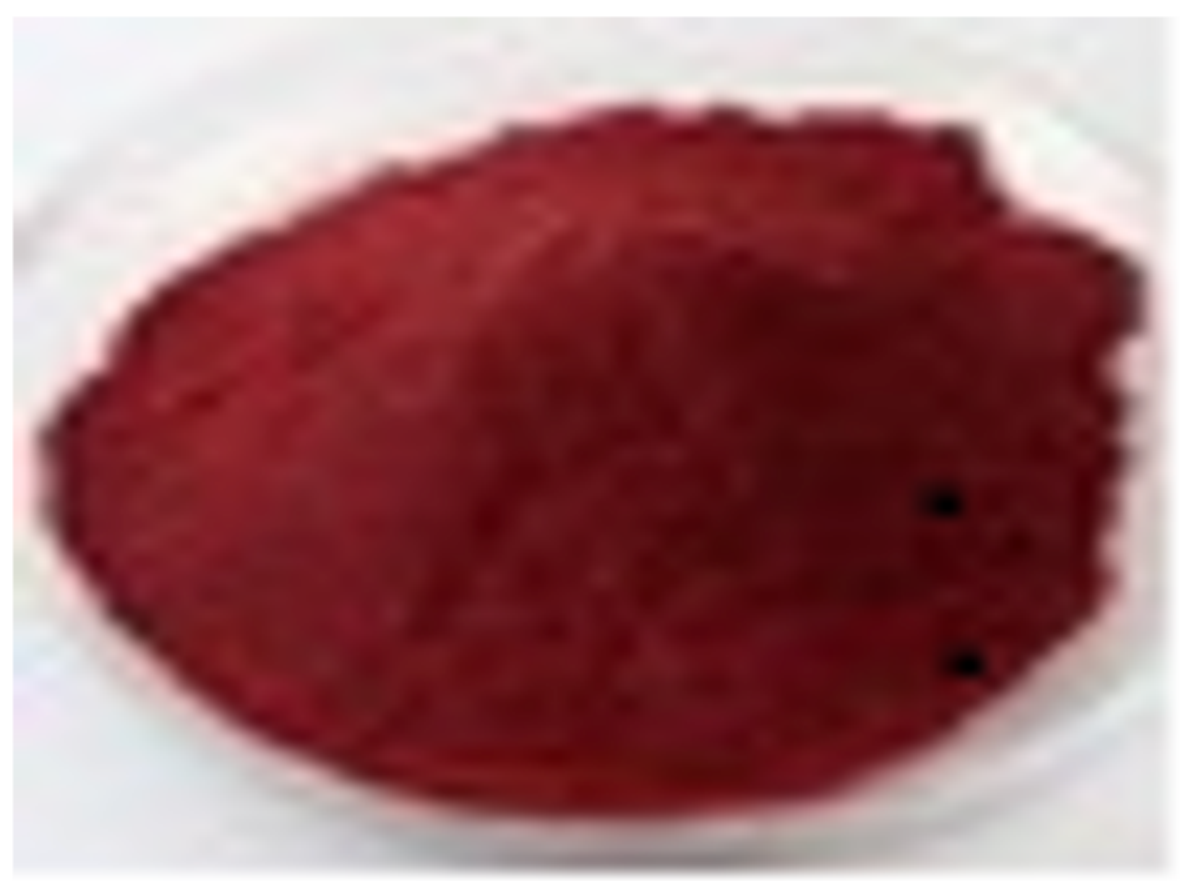

Figure 4

Betanin powder of yellow-brown color 


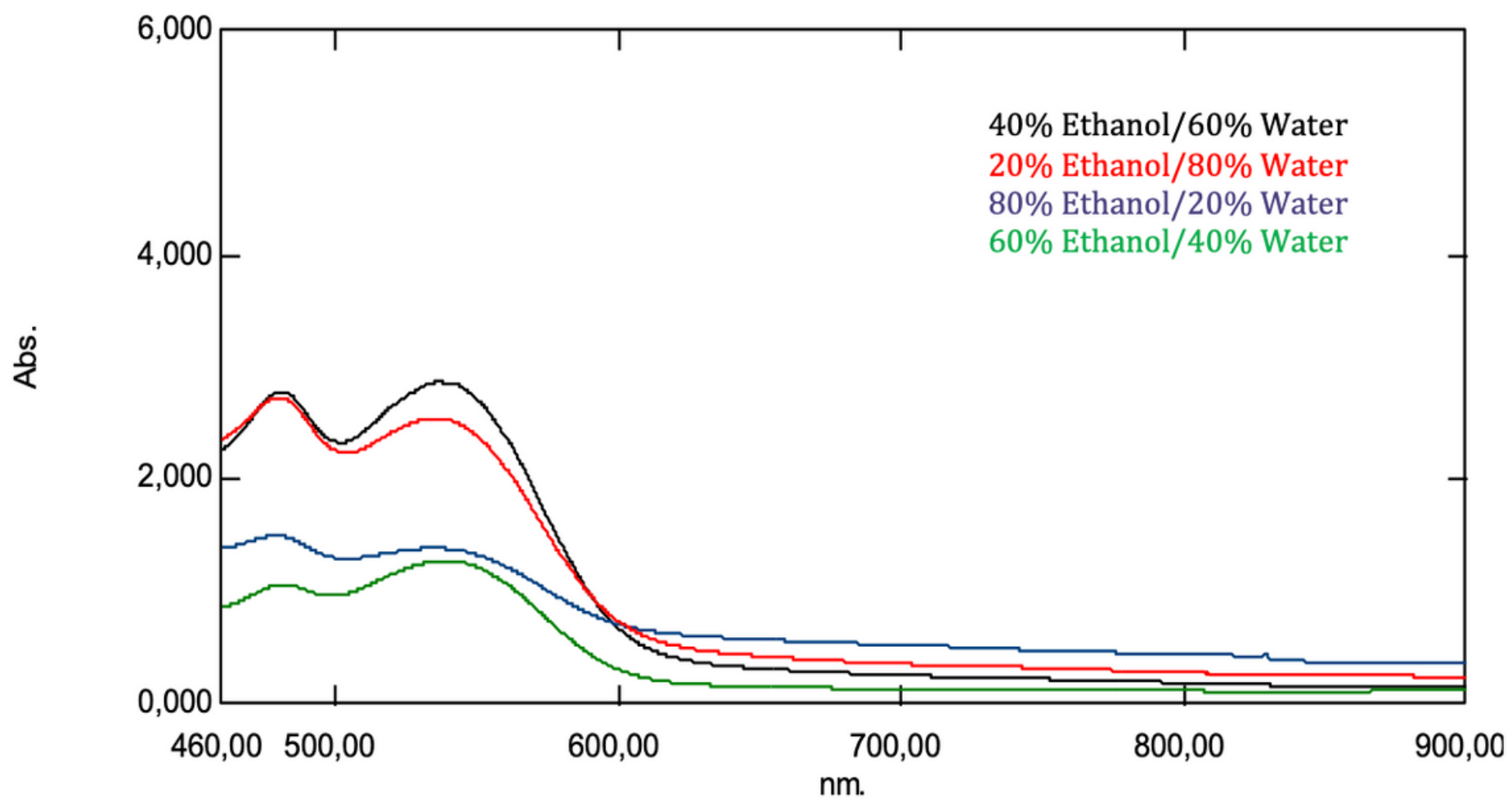

Figure 5

Uv-Visible absorption spectrum Beetroot extracts (\% Ethanol /\% Water)

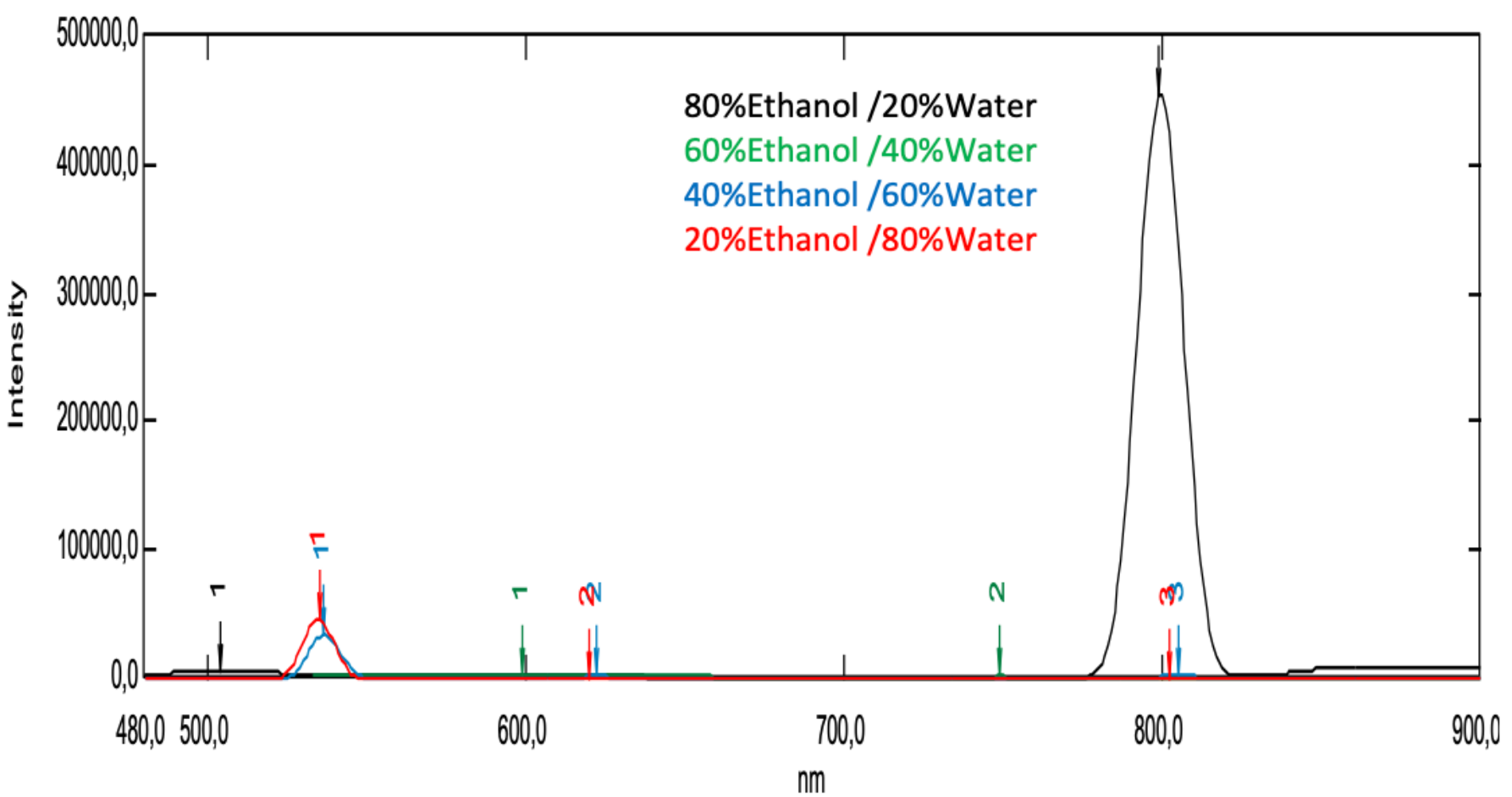

Figure 6

Uv-Visible emission spectrum Beetroot extracts (\% Ethanol /\% Water) 